\title{
Cytokine induction by Gram-positive bacteria
}

\author{
Christian Draing ${ }^{\mathrm{a}}$, Stefanie Sigel ${ }^{\mathrm{a}}$, Susanne Deininger ${ }^{\mathrm{a}}$, Stephanie Traub $^{\mathrm{a}}$, \\ Rebekka Munke ${ }^{\mathrm{a}}$, Christoph Mayer ${ }^{\mathrm{b}}$, Lars Hareng ${ }^{\mathrm{a}, \mathrm{c}}$, Thomas Hartung ${ }^{\mathrm{a}, \mathrm{c}}$, \\ Sonja von Aulock ${ }^{\mathrm{a}}$, Corinna Hermann ${ }^{\mathrm{a}, *}$ \\ ${ }^{a}$ Biochemical Pharmacology, University of Konstanz, 78457 Konstanz, Germany \\ ${ }^{\mathrm{b}}$ Biochemical Microbiology, University of Konstanz, 78457 Konstanz, Germany \\ ${ }^{\mathrm{c}}$ European Centre for the Validation of Alternative Methods, JRC, 21020 Ispra, Italy
}

\begin{abstract}
Despite similar clinical relevance of Gram-positive and Gram-negative infections, immune activation by Grampositive bacteria is by far less well understood than immune activation by Gram-negative bacteria. Our group has made available highly purified lipoteichoic acids (LTA) as a key Gram-positive immunostimulatory component. We have characterized the reasons for lower potency of LTA compared to Gram-negative lipopolysaccharide (LPS), identifying lack of IL-12/IFN $\gamma$ induction as a general characteristic of TLR2 agonists, and need for presentation of LTA on surfaces for enhanced immunostimulatory potency, as major aspects. Aspects of chemokine induction, where LTA is more potent than LPS, have been addressed. Furthermore, novel complement and plant defence activation, as well as CD36 as a new LTA receptor, were identified. The bacterial costimuli and modulators of LTA inducible responses are being investigated: LTA isolated from so far 16 bacterial species, although different in structure, behave remarkably similar while whole live and killed bacteria differ with regard to the pattern of induced responses. The purification and characterization of the respective components of the bacterial cell wall has begun.
\end{abstract}

Keywords: Inate immunity; Gram-positive bacteria; Lipoteichoic acid; Cytokines; Monocytes

\section{Introduction}

The clinical symptoms of Gram-positive and Gramnegative sepsis are almost indistinguishable. While immune activation by lipopolysaccharide (LPS, endotoxin), the major constituent of the cell wall of Gramnegative bacteria, has been extensively characterized, the pathogenesis of Gram-positive sepsis has not yet been attributed to a common structural component. The cell

\footnotetext{
${ }^{*}$ Corresponding author.

E-mail address: corinna.hermann@uni-konstanz.de (C. Hermann).
}

wall of Gram-positive bacteria contains lipoteichoic acids (LTA), which protrude from the cytoplasmic membrane through the murein sacculus (peptidoglycan, PGN). LTA makes up about $2 \%$ of the dry cell weight, and $6 \mathrm{~mol} \%$ of the cytoplasmic membrane (Gutberlet et al., 1997). LTA is found in almost all Gram-positive bacteria (apart from a few laboratory mutants) and is therefore much more common than teichoic acid (TA), the production of which depends on the culture conditions (Wicken and Knox, 1975). TA and LTA stem from different metabolic pathways (Fischer et al., 1990). 
The amphiphilic LTA from most Gram-positive bacterial strains is generally made up of a hydrophilic backbone with repetitive glycerophosphate units and D-alanine or $N$-acetylglucosamine substituents, and a lipophilic glycolipid anchor. A second type of LTA structure is described for Streptococcus pneumoniae, Streptococcus oralis and Streptococcus mitis (Abeygunawardana et al., 1991; Behr et al., 1992; Fischer, 1997; Hogg et al., 1997). The glycerophosphate in the backbone is replaced by a pentamer repeating unit composed of ribitol and a tetrasaccharide. As substituents of the pneumococcal backbone, only phosphorylcholine and $N$-acetyl-D-galactosamine were found. The lipid anchor is usually a dihexosyldiacylglycerol or trihexosyldiacylglycerol, depending on the lipids available in the plasma membrane which differ between species (Fischer, 1988).

Since the conventional extraction methods resulted in a decomposition of LTA resulting in a decrease in its immunostimulatory potency, we developed a method using butanol/water extraction to isolate highly pure and biologically active LTA from Staphylococcus aureus (Morath et al., 2001), the structure of which was elucidated and verified by chemical analysis and synthesis (Stadelmaier et al., 2003). Structure-function relationships were investigated by means of different synthetic derivatives by us (Morath et al., 2002a; Deininger et al., 2003) and LTA was found to be an agonist of TLR2/6 (Lehner et al., 2001; Morr et al., 2002). A recent publication (Travassos et al., 2004), as well as our own findings shows that LTA most likely is a major immunostimulatory principle of PGN, which also possess TLR2 agonistic activity if not sufficiently purified. Furthermore, stimulation with LPS and LTA leads to different cytokine release patterns, which in the case of LTA are characterized by a strong chemokine induction (von Aulock et al., 2003) and almost no IL-12 and IFN $\gamma$ induction (Hermann et al., 2002), which might be explained by the use of different TLR (Hermann et al., 2002). Substitution of IL-12 increases LTA-inducible IFN $\gamma$ release drastically (Hermann et al., 2002) and LTA has been shown to fail to induce remodelling of the IL-12 promoter (Albrecht et al., 2004).

Our further studies focused on the following:

- induction of IL-12 and IFN $\gamma$ by various TLR2 agonists in whole blood;

- comparison of IFN $\gamma$ induction of LTA in human and murine cell populations;

- synergism between LTA and other Gram-positive products;

- identification of IFN $\gamma$-inducing principle in Grampositive bacteria;

- immune stimulatory capacity of LTA bound to surfaces;
- mechanism of enhanced IL-8 release by LTA;

- isolation and characterization of co-stimulatory and modulatory components for LTA action from Grampositive bacteria.

Beside these, collaboration within the DFG high priority program stimulated various collaborative projects, which shall be summarized.

\section{Induction of IL-12 and IFN $\gamma$ by various TLR2 agonists in whole blood}

A range of different TLR2 agonists were tested for their ability to induce IFN $\gamma$ in human whole blood (unpublished). These were LTA from S. aureus, Listeria monocytogenes or Lactobacillus plantanum, synthetic $\mathrm{Pam}_{3}$ Cys, LPS from $B$. fragilis and $P$. gingivalis, PGN from five different species, MALP-2, LTA from Listeria, borrelia lysate, zymosan, pansorbin. Although they all induced TNF release, none of these stimuli were able to induce significant amounts of IFN $\gamma$. Measurement of IL-12 mRNA induction by the different TLR2 stimuli revealed that the $\mathrm{p} 40$ subunit is induced by the TLR2 stimuli, however, at far lower levels than by the same concentration of LPS. Fig. 1 shows representative data for some of the TLR2 agonists employed regarding TNF. The measurements of the IL12p35 subunit mRNA indicated that this is expressed constitutively and not induced significantly by stimulation with the TLR2 agonists. In conclusion, the poor induction of IL-12 and IFN $\gamma$ appears to be a general characteristic of TLR2 agonists in human whole blood, in line with

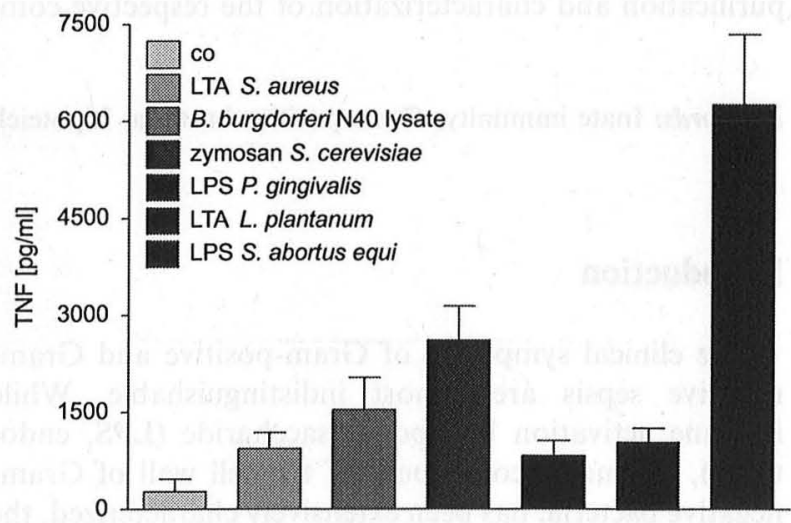

Fig. 1. Cytokine induction of TLR2 agonists in human whole blood in comparison to LPS from Salmonella abortus equi. Human whole blood from four healthy volunteers was incubated in the presence of $10 \mu \mathrm{g} / \mathrm{ml}$ LTA from $S$. aureus and $L$. plantanum, LPS from $P$. gingivalis and $S$. abortus equi, B. burgdorferi $\mathrm{N} 40$ lysate and Zymosan from $S$. cerevisiae for $22 \mathrm{~h}$. TNF release was measured in the cell-free supernatant by ELISA. Data are means \pm SEM. 
recent reports on murine macrophages (Hirschfeld et al., 2001).

\section{Comparison of IFN $\gamma$ induction of LTA in human and murine cell populations}

To check whether the different TLR2 agonists employed above follow the same cytokine induction pattern in murine as in human cells, they were used to stimulate bone marrow cells of mice. All TLR2 agonists were able to induce the release of the pro-inflammatory monokine IL-6 and were again shown to be dependent on TLR2, however, they differed in their ability to induce IFN $\gamma$ : MALP-2 and PGN from some Grampositive bacterial species induced detectable levels of IFN $\gamma$ in murine bone marrow cells, while $\mathrm{Pam}_{3} \mathrm{Cys}$ and other PGN, like LTA as shown previously, did not.

To test whether the inability of LTA to stimulate IFN $\gamma$ translates to other immune cell populations, various monocyte and macrophage-containing cell populations were isolated from mice, i.e. bone marrow cells, peritoneal lavage, bronchoalveolar lavage, spleen cells and whole blood. Although LTA induced the release of TNF in all these cell populations, it did not induce IFN $\gamma$ release, except in spleen cells. This observation was followed up by measuring the release of IL-12p40 and IFN $\gamma$ in the same samples. Here, an induction of IL-12p40 above background levels could be observed.

\section{Synergism between LTA and other Gram-positive products}

Whole blood incubations were performed in which combinations of LTA with Staphylococcal enterotoxin B (SEB), CpG-DNA (synthetic DNA-oligonucleotides) and muropeptides were employed and compared to the inductive capacity of the stimuli by themselves. SEB is a superantigen that induces the release of IFN $\gamma$ by crosslinking MHC II of monocytes and TCR of lymphocytes independent of specifically presented antigens. This induces IFN $\gamma$ release by lymphocytes and TNF release by monocytes. This model was established and characterized in detail by our group (Hermann et al., 2003). A matrix of combinations of LTA and SEB concentrations was employed to stimulate whole blood. However, there was no significant increase of the IFN $\gamma$ release by the addition of LTA either after $24 \mathrm{~h}$ or after $72 \mathrm{~h}$ of incubation (during which time the IFN $\gamma$ level still increases 5-fold).

Neither endotoxin-free muropeptides, e.g. muramyldipeptide (MDP), which are components of the murein sacculus of Gram-positive bacteria, nor CpG-DNA induced significant IFN $\gamma$ release in human whole blood by themselves. MDP is known to synergize with LPS regarding TNF and IFN $\gamma$ induction (Traub et al., 2004, 2006). However, we found that addition of MDP to LTA was not able to induce IFN $\gamma$ release in human whole blood. In a collaboration using our LTA from $S$. aureus and LTA of $S$. pneumoniae a synergistic effect regarding TNF release was found using PBMC but only in the presence of $2.5 \%$ serum (Schroder et al., 2003b).

$\mathrm{CpG}$ oligonucleotides have been reported to possess counterinflammatory effects on LPS-induced IFN $\gamma$ release in whole blood (Smith et al., 2004), in contrast, they potentiate LPS-induced IFN $\gamma$ by increasing IL-12 and IL-18 production in rodents (Gould et al., 2004; Theiner et al., 2008). We could reproduce the finding of Smith et al. in whole blood and found a trend towards increased LTA-induced TNF release and induction of low levels of IFN $\gamma$ by combining LTA and $\mathrm{CpG}$, despite neither component being able to induce IFN $\gamma$ alone. Interestingly, the control oligonucleotides that have a GC sequence instead of $\mathrm{CpG}$ had the same effects as the oligonucleotides with the $\mathrm{CpG}$ sequence regarding both interaction with LPS and LTA. This implies that these effects are not specific to $\mathrm{CpG}$ sequences. The induction of IFN $\gamma$ by the combination of LTA and DNA oligonucleotides could be explained by reports in literature, which describe that the oligonucleotides act via TLR9, i.e. should not interfere with TLR2 mediated LTA signalling, and induce high levels of IL-12 release (Dalpke et al., 2002), thereby substituting the missing component necessary to induce IFN $\gamma$ together with the TNF coming from the LTA stimulation. The increase in TNF release can be explained by a positive feedback of IFN $\gamma$ to the monocyte (Hermann et al., 2003).

\section{Identification of the IFN $\gamma$-inducing principle in Gram-positive bacteria}

We used differently treated $S$, aureus to stimulate whole blood. Washed $S$. aureus were able to induce IFN $\gamma$ release within $24 \mathrm{~h}$ of incubation whether they were live, heated to $70^{\circ} \mathrm{C}$ for $30 \mathrm{~min}$, autoclaved, UV-inactivated or sonicated. The higher activity of the live $S$. aureus compared to the different variations of killed bacteria is probably due to the bacteria still multiplying during the incubation time. We also tested whether the bacteria release any stimulatory activity into the medium during culture and found inductive capacity for TNF as well as IFN $\gamma$ release. As we suspected this activity might stem from staphylococcal enterotoxins, the culture supernatant was employed in a $72 \mathrm{~h}$ incubation in comparison to SEB, LTA and whole killed $S$. aureus. After $72 \mathrm{~h}$ similar amounts of IFN $\gamma$ had been released by stimulation with $5 \%$ of the supernatant as by stimulation with SEB $(100 \mathrm{ng} / \mathrm{ml})$. In comparison, even $10^{7}$ killed $S$. aureus per $\mathrm{ml}$ were not able to induce such high levels of IFN $\gamma$. The release of other 
lymphokines, i.e. IL-2 and IL-5, was measured in the same samples. Here, neither the $S$. aureus nor LTA induced IL-2 or IL-5 release; however, the culture supernatant did so, albeit at lower levels than SEB (own unpublished observation). From these results we conclude that the IFN $\gamma$, IL-2 and IL-5 inducing activity in the culture supernatant was probably an enterotoxin. We further characterized cytokine induction by SEB in isolated cell populations and found that a combination of monocytes and lymphocytes are necessary to induce both IFN $\gamma$ and TNF release (Hermann et al., 2003). This implies that the combination of LTA and enterotoxin in Gram-positive infection could complete a cytokine pattern similar to LPS and so result in similar manifestations of disease, despite no synergism of the two components. However, the fact that killed $S$. aureus induce IFN $\gamma$ implies that also a constitutive IFN $\gamma$ inducing principle exists.

\section{Immune stimulatory capacity of LTA bound to surfaces}

Initial observations indicated that overnight binding of LTA to polystyrene surfaces leads to an increased TNF release from whole blood, although the wells were washed twice with saline to remove unbound LTA. To further extend this finding, we incubated LTA and LPS in concentration response curves on a polystyrene plate overnight. The next day the supernatants of all wells were collected and used to stimulate whole blood (Fig. 2, supernatant). The wells were washed twice with saline and were incubated with whole blood as well (Fig. 2, coat) and TNF induction was compared to stimulation with the same concentration of soluble stimulus added together with the blood (Fig. 2, soluble). We found that as little as $200 \mathrm{ng}$ LTA in the coating solution (coat) per well sufficed to induce TNF release and $20 \mathrm{ng}$ sufficed to induce IL- 8 release, while $2 \mu \mathrm{g}$ of soluble LTA per well was necessary to induce significant cytokine release from whole blood, when given no time for coating. The immunostimulatory potency of the remaining supernatants was comparable to that of freshly added soluble LTA, indicating that only minor quantities of LTA had adhered to the well surface during the overnight incubation. This increased cytokine-inducing activity of coated LTA also translated to IL-1 $\beta$, IL- 6 and G-CSF release, while the release of IL-10 was not altered. This was furthermore reflected on the mRNA level. Surprisingly, no such "coat" effect was observed for LPS, as TNF release by the supernatant or by soluble LPS was greater than that induced by coat LPS at all concentrations (Deininger et al., in press).

To determine how much of the LTA had in fact bound to the well surface during the overnight incubation, we developed a protocol to label LTA with rhodamine. The labelling efficiency was $1-2$ rhodamine molecules per LTA. The results obtained with the rhodamine-labelled LTA showed that after $24 \mathrm{~h}$ of incubation with $2 \mu \mathrm{g}$ LTA per well, only about $4 \%$ of the LTA (i.e. $80 \mathrm{ng}$ ) remained bound to the well (Deininger et al., in press), which is in line with our observation that the supernatant collected from the LTA-coated wells exerted comparable immunostimulatory potency as the same concentration of soluble LTA, and furthermore underlines the enormous increase in potency (about 1000-fold) in immune activation obtained by surface-presented LTA.

To gain more insight into the type of presentation necessary to increase the stimulatory capacity of LTA, we let LTA interact with different surfaces including polystyrene, polypropylene and glass, which differ in their polarity. We found that although LTA bound to polypropylene in a comparable manner as to polystyrene, only a minor increase in immune stimulation was observed. Furthermore, stimulation of blood with LTA in glass vials induced hardly any cytokine release, independent of whether the LTA was preincubated with the surface or added together with the blood. To rule out possible effects of the silicone-coated glass, we coupled LTA to polymer beads and used these to induce cytokine secretion in the glass vials. These LTA-linked beads, like live and inactivated $S$. aureus bacteria, were able to stimulate cytokine secretion in silicone borosilicate tubes, showing that the silicone borosilicate surface itself did not interfere with cytokine induction by LTA and this cytokine induction was comparable to that in polypropylene tubes. This indicates that LTA does not adhere to glass and that presentation of LTA is an absolute requirement for immune stimulation by LTA and not only an amplifier of its activity.

The coat effect might be interpreted as the crosslinking of individual LTA molecules. We synthesized, based on our first synthesis of LTA (Morath et al., 2002a), an artificial bisamphiphilic LTA modelling a fixed cross-linkage of two LTA molecules (FigueroaPerez et al., 2006). This bisamphiphilic LTA induced higher TNF and IL-8 levels than soluble monoamphiphilic LTA at the same molarity, indicating that the increase in potency of the bound LTA may stem from cross-linkage of receptors. Augmentation of LTA activity by cross-linking has been suggested earlier in experiments with anti-polyglycerophosphate antibodies (Mancuso et al., 1994). Together, these results suggest that the increased activity of bound LTA might lie in receptor clustering.

In vivo, the LTA is anchored in the cytoplasmic membrane and projects through the murein sacculus. With regard to induction of immune responses many similarities exist between PGN of Gram-positive bacteria and LTA, like strong induction of IL-8 and dependence on TLR2. Since we showed that PGN from 

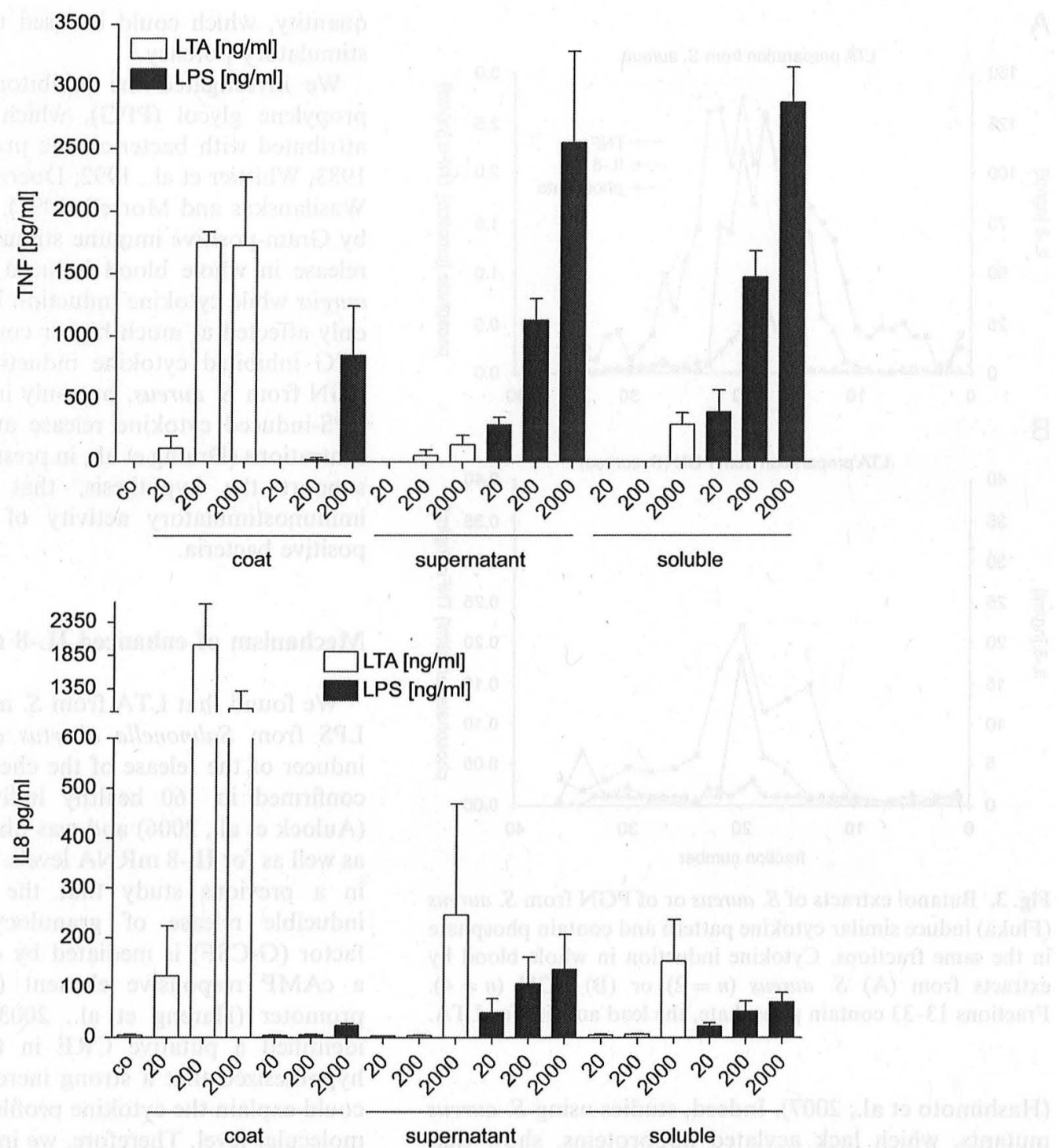

Fig. 2. Surface presentation of LTA but not LPS increases the cytokine release capacity. Human whole blood from three healthy volunteers was stimulated with increasing concentrations of LTA coated to polystyrene plates, with supernatant of the coated LTA or of soluble LTA. After $22 \mathrm{~h}$ TNF and IL-8 release were measured in the cell-free supernatants by ELISA. The cytokine release by the unstimulated controls was below the detection limit. Data are means \pm SEM.

Gram-negative bacteria displays no TLR2-dependent activity, it was tempting to speculate that minor quantities of LTA remaining in PGN preparations might represent a main immune active component. Therefore, we attempted to extract LTA from commercial $S$. aureus PGN preparation. The elution profile presented both cytokine-inducing activity (TNF and IL-8) and phosphate content (lead activity for LTA) in fractions that typically contain LTA (Fig. 3). The amount of LTA eluted was estimated at 10-20 $\mu \mathrm{g}$ based on cytokine induction and phosphate content. The presence of LTA in the respective pool fraction was indicated by representative NMR resonances of glycerol methine $\left(\delta_{\mathrm{H}} 5.4\right)$, the anomeric proton of $\alpha$-D-Nacetylglucosamine $\left(\delta_{\mathrm{H}} 5.08\right)$, methyl $\left(\delta_{\mathrm{H}} \quad 0.8\right)$ and methylene $\left(\delta_{\mathrm{H}} 1.3\right)$. Thus, commercial PGN indeed does contain a small amount of LTA (own unpublished observation), which is in line with work of Travassos et al. (2004) who claim that highly purified PGN, from which possible LTA and lipoprotein contaminations are removed, lacks immune stimulatory activity. The purity of preparations of pathogen-associated immune stimulatory components are of great importance and a major issue of discussion to date. Currently it is discussed whether lipoproteins and not LTA are the main active, TLR2-dependent principle of Gram-positive bacteria 


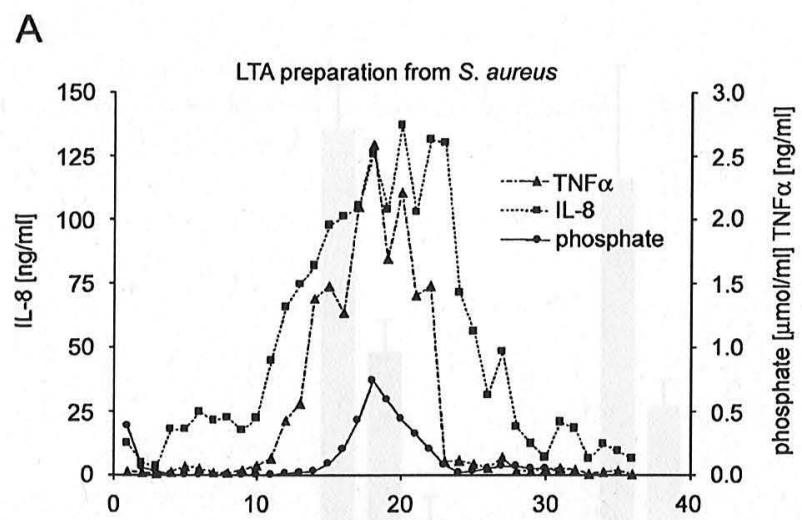

B

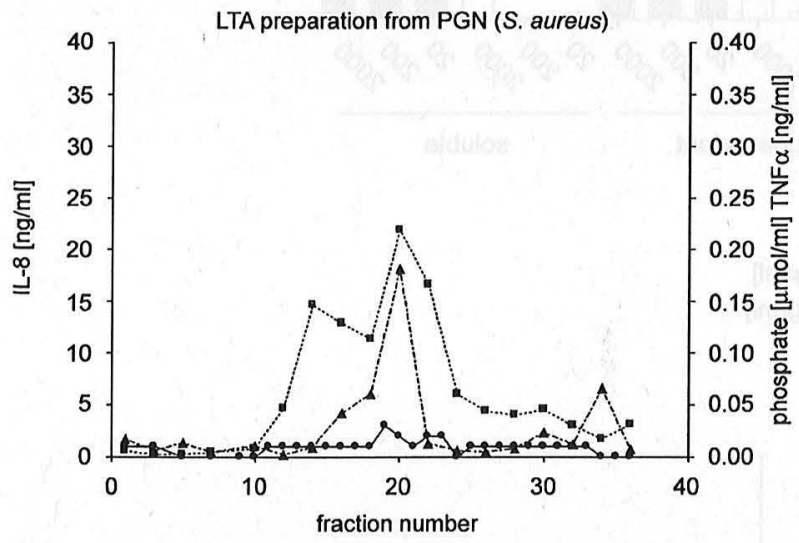

Fig. 3. Butanol extracts of $S$. aureus or of PGN from $S$. aureus (Fluka) induce similar cytokine pattern and contain phosphate in the same fractions. Cytokine induction in whole blood by extracts from (A) $S$. aureus $(n=2)$ or (B) PGN $(n=4)$. Fractions 13-33 contain phosphate, the lead activity for LTA.

(Hashimoto et al., 2007). Indeed, studies using S. aureus mutants, which lack acylated lipoproteins, show that this $S$. aureus mutant induces much lower pro-inflammatory cytokine release (Stoll et al., 2005) compared to the wild-type $S$. aureus strain, and furthermore leads to lethal disseminated infection in mice by failing to elict adequate immune responses (Bubeck Wardenburg et al., 2006). It was further reported that LTA prepared from the $S$. aureus mutant, lacking acylated lipoproteins, lacks immunobiological activity (Hashimoto et al., 2006). The latter publication was rebutted (von Aulock et al., 2007) by showing that LTA prepared from the same $S$. aureus mutant possesses cytokine inducing activity comparable to LTA prepared from a wild-type $S$. aureus strain in human whole blood. Whether this controversy is due to differences in the preparation method or experimental setting remains to be defined. Anyhow, so far, in none of the LTA preparations prepared by our group was lipoprotein contamination detected or isolated. Furthermore, so far no lipoproteins have been extracted from bacteria in high purity or quantity, which could be used to study their immune stimulatory potency.

We investigated the inhibitory properties of polypropylene glycol (PPG), which had previously been attributed with bacteriostatic properties (Chirife et al., 1983; Whittier et al., 1992; Doern and Westerling, 1994; Wasilauskas and Morrell, 1994), on cytokine induction by Gram-positive immune stimuli. PPG inhibited TNF release in whole blood induced by UV-inactivated $S$. aureus while cytokine induction by Escherichia coli was only affected at much higher concentrations. Similarly, PPG inhibited cytokine induction by either LTA or PGN from $S$. aureus, but only interfered partially with LPS-induced cytokine release at 100 -fold higher concentrations (Draing et al., in press). These results further support the hypothesis, that LTA represents the immunostimulatory activity of the PGN of Grampositive bacteria.

\section{Mechanism of enhanced IL-8 release by LTA}

We found that LTA from $S$. aureus in comparison to LPS from Salmonella abortus equi is a more potent inducer of the release of the chemokine IL-8. This was confirmed in 160 healthy individuals of both sexes (Aulock et al., 2006) and was observed for IL-8 protein as well as for IL-8 mRNA levels. We had already shown in a previous study that the similar strong LTAinducible release of granulocyte colony-stimulating factor (G-CSF) is mediated by cAMP, which binds to a cAMP responsive element (CRE) in the G-CSF promoter (Hareng et al., 2003). Since we had also identified a putative CRE in the IL- 8 promoter we hypothesized that a strong increase of cAMP by LTA could explain the cytokine profile induced by LTA on a molecular level. Therefore, we inserted the IL-8 promoter region upstream of a luciferase gene and introduced disruptive point mutations into the $\mathrm{NF} \kappa \mathrm{B}$ and the AP1 binding as well as in the putative CRE site by sitedirected mutagenesis (Fig. 4A). While the addition of LPS and LTA resulted in a 3-fold increase of luciferase activity in HL-60 cells transfected with the intact promoter construct (HL-60-WT), the introduction of the construct containing a disrupted $\mathrm{NF} \kappa \mathrm{B}$ or AP1 binding site led to 10 -fold lower basal luciferase levels than HL-60-WT. In contrast, comparable basal and inducible luciferase expression was found in HL-60 cells transfected with the disrupted CRE reporter gene, indicating no functional role of the CRE in mediating IL-8 promoter activity (Fig. 4B, own unpublished oberservation). Since LPS is a TLR4 agonist and LTA an agonist of TLR2, it is most likely that differences in signal transduction pathways downstream of the TLRs are responsible for the differences in the cytokine release patterns induced by LPS and LTA. Our recent data 
A

\begin{tabular}{|c|c|c|c|c|}
\hline & -164 & -126 & -82 & +1 \\
\hline & CRE & $\mathrm{AP}-1$ & NFKB & Luciferase \\
\hline wt & TTTCGTCA & TGACTCA & TGGAATTTCC & \\
\hline mut & TTTTCGGT & TATCTCA & TTAACTTTCC & \\
\hline
\end{tabular}

B

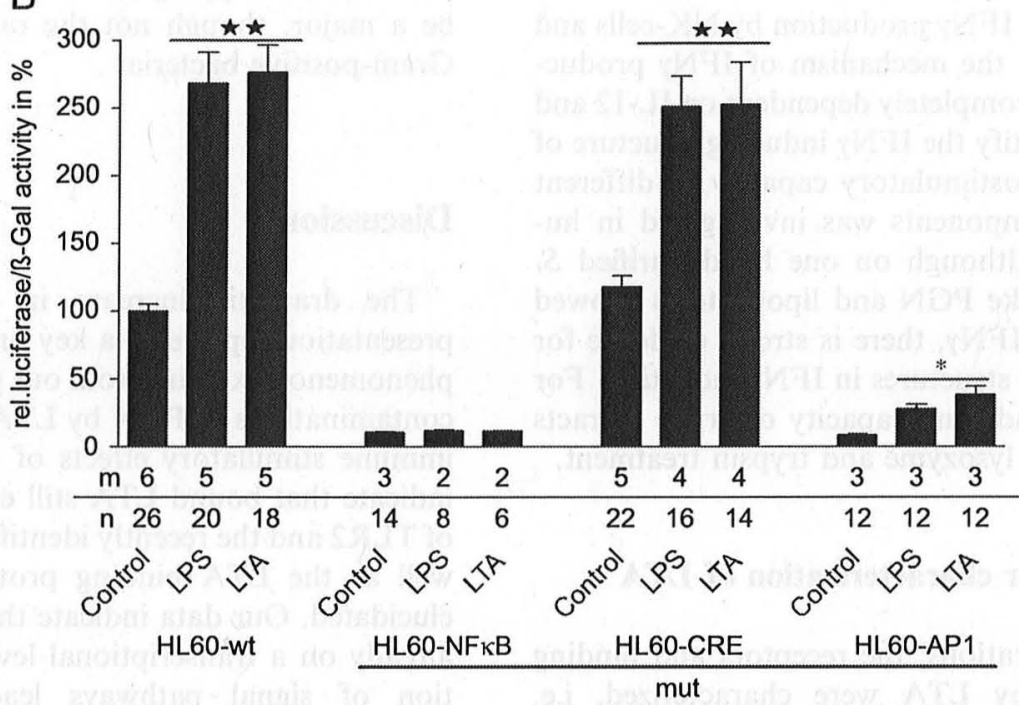

Fig. 4. Luciferase activity in HL-60 cells transfected with IL-8 promoter dependent reporter gene constructs. (A) The human minimal IL-8 promoter was introduced into the pGL3-enhanced vector (wt construct). Underlined letters indicate the nucleotide exchanges, introduced either into the $\mathrm{NF} \kappa \mathrm{B}, \mathrm{AP1}$ binding site or $\mathrm{CRE}$ of the wt construct by site-directed mutagenesis, resulting in the NF $\kappa$ Bmut, APlmut and CREmut constructs. (B) HL-60 cells were transiently transfected with the respective constructs and were stimulated with $10 \mu \mathrm{g} / \mathrm{ml}$ LPS or LTA for $16 \mathrm{~h}$ and luciferase/ $\beta$-galactosidase activity was assessed in the cell lysates. Luciferase data are normalized to the respective $\beta$-galactosidase activity and expressed as $\%$ of the mean (unstimulated HL60-wt) \pm SEM. Data are pooled from independent experiments ( $n=$ total replicates, $m=$ number of experiments). ${ }^{*}$ and $* *$ indicate significantly different luciferase activity compared to the unstimulated control.

show that although activation of the MAP kinases p38 and ERK1/2 is comparable between LPS and LTA, LTA fails to activate Jun kinase (Hermann et al., 2006).

In order to identify the blood cell fraction responsible for predominant IL-8 induction by LTA, we isolated PBMC and found that in contrast to whole blood, PBMC stimulation with LPS or LTA resulted in similar IL-8 levels. While the addition of neutrophilic granulocytes had no effect on LPS- or LTA-induced IL-8 levels, the addition of isolated erythrocytes to PBMC resulted in 3-fold higher LTA triggered IL-8 levels compared to LPS. Stimulation with erythrocyte fractions alone resulted in no significant IL-8 release. To investigate whether LPS or LTA might be bound by erythrocytes and presented to the immune cells, LTA and LPS were labelled with rhodamine, incubated with erythrocytes and analyzed by FACS. A 3-fold higher rhodamine fluorescence signal was detectable after incubation of labelled LTA compared to LPS, indicating a more pronounced binding of LTA to the erythrocyte in comparison to LPS (own unpublished observation).

Taken together, these findings indicate that possibly by the binding of LTA to erythrocytes, the LTA is presented to the monocytes in a more efficient way, leading to enhanced IL-8 release. This is in line with our general findings that the type of LTA presentation is crucial for its immune stimulating activity, while the potency of LPS is not affected by presentation.

\section{Isolation and characterization of co-stimulatory and modulatory components for LTA action from Gram- positive bacteria}

One of the most prominent differences in the immune activation by LTA versus whole bacteria is the lack of IL-12/IFN $\gamma$ induction. We have shown that bacterial DNA and enterotoxin like SEB might be a synergist complementing LTA in whole bacteria. Since more recently we found that IFN $\gamma$ induction can be obtained also by crude, supernatant-free extracts of bacterial membranes, which are also DNA-free, we speculate that there are also IL-12/IFN $\gamma$ inducing components in the bacterial wall, which were isolated to characterize the $S$. aureus mediated production of IFN $\gamma$ and to identify 
the components responsible for the release of this cytokine.

In order to characterize the type of IFN $\gamma$ producing cells, human whole blood was stimulated with $S$. aureus lysate and IFN $\gamma$ producing cells were analyzed by flow cytometry. Like for LPS, stimulation of whole blood with $S$. aureus lead to IFN $\gamma$ production by NK-cells and $\mathrm{T}$-cells. Furthermore, the mechanism of IFN $\gamma$ production was found to be completely dependent on IL-12 and TNF release. To identify the IFN $\gamma$ inducing structure of $S$. aureus the immunostimulatory capacity of different purified bacterial components was investigated in human whole blood. Although on one hand purified $S$. aureus components like PGN and lipoproteins showed no or low release of IFN $\gamma$, there is strong evidence for participation of those structures in IFN $\gamma$ induction. For example, the IFN $\gamma$-inducing capacity of crude extracts was sensitive to both lysozyme and trypsin treatment.

\section{Collaborative further characterization of LTA}

In various collaborations, the receptors and binding proteins employed by LTA were characterized, i.e. TLR2 (Lehner et al., 2001; Michelsen et al., 2001; Opitz et al., 2001; Pfeiffer et al., 2001; Ellingsen et al., 2002; Schroder et al., 2003a; Lotz et al., 2004; Netea et al., 2004; Triantafilou et al., 2004a, b; von Aulock et al., 2004; Dalpke et al., 2005; Liljeroos et al., 2007; Spiller et al., 2007), CD14 (Hermann et al., 2002; Lotz et al., 2004; Hattar et al., 2005), partially LBP (Hermann et al., 2002; Mueller et al., 2006), surfactant proteins (van de Wetering et al., 2001), CD36 (Hoebe et al., 2005; Triantafilou et al., 2006) and TLR6 (Triantafilou et al., 2006). The following elements of the signal transduction were identified: Bruton's kinase (Liljeroos et al., 2007), JNK (Hermann et al., 2006), potassium channels (Scheel et al., 2006), protein kinase B (Dahle et al., 2004), IRAK (Jacinto et al., 2002; Dahle et al., 2004), p38 and ERK (Hermann et al., 2006). Parallel work identified LTA structures from various species (Morath et al., 2002b; Grangette et al., 2005; Henneke et al., 2005; Draing et al., 2006; Palumbo et al., 2006) and confirmed activities and minimal active structures by chemical synthesis (Morath et al., 2002a, 2005; Deininger et al., 2003; Stadelmaier et al., 2003, 2006; FigueroaPerez et al., 2006). Various cell types besides monocytes used in our studies were shown to be activated: glial cells (Kinsner et al., 2005, 2006; Lund et al., 2005; Boveri et al., 2006), partially neutrophils (von Aulock et al., 2003; Lotz et al., 2004, 2006; Hattar et al., 2006), cardiac cells (Grandel et al., 2005), Kupffer cells (Dahle et al., 2004), endothelial cells (Hermann et al., 2002; Yipp et al., 2002) and dendritic cells (Michelsen et al., 2001). Furthermore, novel mechanisms of complement activation (Lynch et al., 2004) and blood coagulation (Mattsson et al., 2004) as well as plant immune defence (Zeidler et al., 2004) were identified.

This work currently involving about 80 groups worldwide using highly purified LTA has established this component as an immune-stimulus with biological activities overlapping but distinct to LPS. It appears to be a major, though not the only immune-stimulus of Gram-positive bacteria.

\section{Discussion}

The dramatic increase in LTA activity due to presentation represents a key finding of this work. This phenomenon explains from our point of view that minor contaminations of PGN by LTA are responsible for the immune stimulatory effects of PGN. Preliminary data indicate that bound LTA still employs CD14. The role of TLR2 and the recently identified co-receptor CD36 as well as the LTA binding protein LBP remain to be elucidated. Our data indicate that the effect takes place already on a transcriptional level. Thus, an augmentation of signal pathways leading to activation of transcription factors is likely. We have been able to show recently that LTA in solution lacks the ability to activate JNK, which might be the underlying reason for lesser potency regarding the induction of pro-inflammatory cytokines. Whether this is changed when LTA is presented on a surface must be explored further.

The enormous potentiation of LTA activity by presentation led to the question of whether LTA monomers in solution can activate monocytes at all. By choosing incubation vials, which do not allow LTA binding, as well as various beads binding LTA, this phenomenon was addressed. In preparation for such studies, a rhodamine-labelled LTA has been produced, which allows tracing and quantification of surface binding. Indeed, when no binding of LTA to surfaces is possible, blood monocytes were not able to react to LTA.

The data presented show that the cytokine pattern induced by LTA is representative for numerous stimuli, which are recognized by TLR2. Induction of IFN $\gamma$ can be realized by co-stimulation of LTA and CpGoligonucleotides, directly with enterotoxin or by presentation of LTA on a surface. A combination of these three factors likely explains why the cytokine spectrum as well as the symptoms of Gram-positive sepsis is so similar to Gram-negative sepsis.

In parallel, numerous collaborations were carried out. While first those endpoints were addressed where LTA fails to match with LPS-inducible cytokine release (IL-12, IFN $\gamma$ ), we later addressed those where LTA is often even more potent than LPS, i.e. G-CSF and IL-8 induction. Finally, the identification of synergizing and modifying immune stimuli was initiated. 
Altogether, this work has shed light on immune recognition of Gram-positive bacteria. LTA appear to represent a major though not stand-alone immune pattern for recognition of Gram-positive bacteria. Its sensitivity and dependence on surface presentation as well as confusion caused by LPS-contaminated commercial preparations has for a long time prohibited its establishment as the Gram-positive endotoxin.

\section{References}

Abeygunawardana, C., Bush, C.A., Cisar, J.O., 1991. Complete structure of the cell surface polysaccharide of Streptococcus oralis C104: a $600-\mathrm{MHz}$ NMR study. Biochemistry $30,8568-8577$.

Albrecht, I., Tapmeier, T., Zimmermann, S., Frey, M., Heeg, K., Dalpke, A., 2004. Toll-like receptors differentially induce nucleosome remodelling at the IL-12p40 promoter. EMBO Rep 5, 172-177.

Aulock, S.V., Deininger, S., Draing, C., Gueinzius, K., Dehus, O., Hermann, C., 2006. Gender difference in cytokine secretion on immune stimulation with LPS and LTA. J. Interferon Cytokine Res. 26, 887-892.

Behr, T., Fischer, W., Peter-Katalinic, J., Egge, H., 1992. The structure of pneumococcal lipoteichoic acid. Improved preparation, chemical and mass spectrometric studies. Eur. J. Biochem. 207, 1063-1075.

Boveri, M., Kinsner, A., Berezowski, V., Lenfant, A.M., Draing, C., Cecchelli, R., Dehouck, M.P., Hartung, T., Prieto, P., Bal-Price, A., 2006. Highly purified lipoteichoic acid from gram-positive bacteria induces in vitro bloodbrain barrier disruption through glia activation: role of proinflammatory cytokines and nitric oxide. Neuroscience 137, 1193-1209.

Bubeck Wardenburg, J., Williams, W.A., Missiakas, D., 2006. Host defenses against Staphylococcus aureus infection require recognition of bacterial lipoproteins. Proc. Natl. Acad. Sci. USA 103, 13831-13836.

Chirife, J., Herszage, L., Joseph, A., Bozzini, J.P., Leardini, N., Kohn, E.S., 1983. In vitro antibacterial activity of concentrated polyethylene glycol 400 solutions. Antimicrob. Agents Chemother. 24, 409-412.

Dahle, M.K., Overland, G., Myhre, A.E., Stuestol, J.F., Hartung, T., Krohn, C.D., Mathiesen, O., Wang, J.E., Aasen, A.O., 2004. The phosphatidylinositol 3-kinase/ protein kinase B signaling pathway is activated by lipoteichoic acid and plays a role in Kupffer cell production of interleukin-6 (IL-6) and IL-10. Infect. Immun. 72, 5704-5711.

Dalpke, A.H., Frey, M., Morath, S., Hartung, T., Heeg, K., 2002. Interaction of lipoteichoic acid and CpG-DNA during activation of innate immune cells. Immunobiology 206, 392-407.

Dalpke, A.H., Lehner, M.D., Hartung, T., Heeg, K., 2005. Differential effects of CpG-DNA in toll-like receptor-2/-4/9 tolerance and cross-tolerance. Immunology 116, 203-212.

Deininger, S., Stadelmaier, A., von Aulock, S., Morath, S., Schmidt, R.R., Hartung, T., 2003. Definition of structural prerequisites for lipoteichoic acid-inducible cytokine induction by synthetic derivatives. J. Immunol. 170, 4134-4138.
Deininger, S., Traub, S., Aichele, D., Rupp, T., Hartung, T., von Aulock, S. Presentation of lipoteichoic acid potentiates its inflammatory activity. Immunobiology, in press, doi:10.1016/j.imbio.2008.01.001.

Doern, G.V., Westerling, J.A., 1994. Optimum recovery of Mycobacterium avium complex from blood specimens of human immunodeficiency virus-positive patients by using small volumes of isolator concentrate inoculated into BACTEC 12B bottles. J. Clin. Microbiol. 32, 2576-2577.

Draing, C., Pfitzenmaier, M., Zummo, S., Mancuso, G., Geyer, A., Hartung, T., von Aulock, S., 2006. Comparison of lipoteichoic acid from different serotypes of Streptococcus pneumoniae. J. Biol. Chem. 281, 33849-33859.

Draing, C., Traub, S., Deininger, S., Mang, P., Möller, H., Manso, M., Rossi, F., Morath, S., Hartung, T., von Aulock, S. Polypropylene glycol is a selective binding inhibitor for LTA and other structurally related TLR-2 agonists. Eur. J. Immunol., in press.

Ellingsen, E., Morath, S., Flo, T., Schromm, A., Hartung, T., Thiemermann, C., Espevik, T., Golenbock, D., Foster, D., Solberg, R., Aasen, A., d Wang, J., 2002. Induction of cytokine production in human $\mathrm{T}$ cells and monocytes by highly purified lipoteichoic acid: involvement of toll-like receptors and CD14. Med. Sci. Monit. 8, BR149-BR156.

Figueroa-Perez, I., Stadelmaier, A., Deininger, S., Aulock, S., Hartung, T., Schmidt, R.R., 2006. Synthesis of Staphylococcus aureus lipoteichoic acid derivatives for determining the minimal structural requirements for cytokine induction. Carbohydr. Res. 341, 2901-2911.

Fischer, W., 1988. Physiology of lipoteichoic acids in bacteria. Adv. Microb. Physiol. 29, 233-302.

Fischer, W., 1997. Pneumococcal lipoteichoic and teichoic acid. Microb. Drug Resist. 3, 309-325.

Fischer, W., Mannsfeld, T., Hagen, G., 1990. On the basic structure of poly(glycerophosphate) lipoteichoic acids. Biochem. Cell Biol. 68, 33-43.

Gould, M.P., Greene, J.A., Bhoj, V., DeVecchio, J.L., Heinzel, F.P., 2004. Distinct modulatory effects of LPS and $\mathrm{CpG}$ on IL-18-dependent IFN-gamma synthesis. J. Immunol. 172, 1754-1762.

Grandel, U., Hopf, M., Buerke, M., Hattar, K., Heep, M., Fink, L., Bohle, R.M., Morath, S., Hartung, T., Pullamsetti, S., Schermuly, R.T., Seeger, W., Grimminger, F., Sibelius, U., 2005. Mechanisms of cardiac depression caused by lipoteichoic acids from Staphylococcus aureus in isolated rat hearts. Circulation 112, 691-698.

Grangette, C., Nutten, S., Palumbo, E., Morath, S., Hermann, C., Dewulf, J., Pot, B., Hartung, T., Hols, P., Mercenier, A., 2005. Enhanced antiinflammatory capacity of a Lactobacillus plantarum mutant synthesizing modified teichoic acids. Proc. Natl. Acad. Sci. USA 102, 10321-10326.

Gutberlet, T., Frank, J., Bradaczek, H., Fischer, W., 1997. Effect of lipoteichoic acid on thermotropic membrane properties. J. Bacteriol. 179, 2879-2883.

Hareng, L., Meergans, T., von Aulock, S., Volk, H.D., Hartung, T., 2003. Cyclic AMP increases endogenous granulocyte colony-stimulating factor formation in monocytes and THP-1 macrophages despite attenuated TNFalpha formation. Eur. J. Immunol. 33, 2287-2296. 
Hashimoto, M., Tawaratsumida, K., Kariya, H., Kiyohara, A., Suda, Y., Krikae, F., Kirikae, T., Gotz, F., 2006. Not lipoteichoic acid but lipoproteins appear to be the dominant immunobiologically active compounds in Staphylococcus aureus. J. Immunol. 177, 3162-3169.

Hashimoto, M., Furuyashiki, M., Kaseya, R., Fukada, Y., Akimaru, M., Aoyama, K., Okuno, T., Tamura, T., Kirikae, T., Kirikae, F., Eiraku, N., Morioka, H., Fujimoto, Y., Fukase, K., Takashige, K., Moriya, Y., Kusumoto, S., Suda, Y., 2007. Evidence of immunostimulating lipoprotein existing in the natural lipoteichoic acid fraction. Infect. Immun. 75, 1926-1932.

Hattar, K., van Burck, S., Bickenbach, A., Grandel, U., Maus, U., Lohmeyer, J., Csernok, E., Hartung, T., Seeger, W., Grimminger, F., Sibelius, U., 2005. Anti-proteinase 3 antibodies (c-ANCA) prime CD14-dependent leukocyte activation. J. Leukoc. Biol. 78, 992-1000.

Hattar, K., Grandel, U., Moeller, A., Fink, L., Iglhaut, J., Hartung, T., Morath, S., Seeger, W., Grimminger, F., Sibelius, U., 2006. Lipoteichoic acid (LTA) from Staphylococcus aureus stimulates human neutrophil cytokine release by a CD14-dependent, toll-like-receptor-independent mechanism: Autocrine role of tumor necrosis factor[alpha] in mediating LTA-induced interleukin-8 generation. Crit. Care Med. 34, 835-841.

Henneke, P., Morath, S., Uematsu, S., Weichert, S., Pfitzenmaier, M., Takeuchi, O., Muller, A., Poyart, C., Akira, S., Berner, R., Teti, G., Geyer, A., Hartung, T., Trieu-Cuot, P., Kasper, D.L., Golenbock, D.T., 2005. Role of lipoteichoic acid in the phagocyte response to group B streptococcus. J. Immunol. 174, 6449-6455.

Hermann, C., Spreitzer, I., Schroder, N.W., Morath, S., Lehner, M.D., Fischer, W., Schutt, C., Schumann, R.R., Hartung, T., 2002. Cytokine induction by purified lipoteichoic acids from various bacterial species - role of LBP, sCD14, CD14 and failure to induce IL-12 and subsequent IFN-gamma release. Eur. J. Immunol. 32, 541-551.

Hermann, C., von Aulock, S., Graf, K., Hartung, T., 2003. A model of human whole blood lymphokine release for in vitro and ex vivo use. J. Immunol. Methods 275, 69-79.

Hermann, C., von Aulock, S., Dehus, O., Keller, M., Okigami, H., Gantner, F., Wendel, A., Hartung, T., 2006. Endogenous cortisol determines the circadian rhythm of lipopolysaccharide - but not lipoteichoic acid - inducible cytokine release. Eur. J. Immunol. 36, 371-379.

Hirschfeld, M., Weis, J.J., Toshchakov, V., Salkowski, C.A., Cody, M.J., Ward, D.C., Qureshi, N., Michalek, S.M., Vogel, S.N., 2001. Signaling by toll-like receptor 2 and 4 agonists results in differential gene expression in murine macrophages. Infect. Immun. 69, 1477-1482.

Hoebe, K., Georgel, P., Rutschmann, S., Du, X., Mudd, S., Crozat, K., Sovath, S., Shamel, L., Hartung, T., Zahringer, U., Beutler, B., 2005. CD36 is a sensor of diacylglycerides. Nature 433, 523-527.

Hogg, S.D., Whiley, R.A., De Soet, J.J., 1997. Occurrence of lipoteichoic acid in oral streptococci. Int. J. Syst. Bacteriol. 47, 62-66.

Jacinto, R., Hartung, T., McCall, C., Li, L., 2002. Lipopolysaccharide- and lipoteichoic acid-induced tolerance and cross-tolerance: distinct alterations in IL-1 receptor-associated kinase. J. Immunol. 168, 6136-6141.

Kinsner, A., Pilotto, V., Deininger, S., Brown, G.C., Coecke, S., Hartung, T., Bal-Price, A., 2005. Inflammatory neurodegeneration induced by lipoteichoic acid from Staphylococcus aureus is mediated by glia activation, nitrosative and oxidative stress, and caspase activation. J. Neurochem. 95 , 1132-1143.

Kinsner, A., Boveri, M., Hareng, L., Brown, G.C., Coecke, S., Hartung, T., Bal-Price, A., 2006. Highly purified lipoteichoic acid induced pro-inflammatory signalling in primary culture of rat microglia through toll-like receptor 2: selective potentiation of nitric oxide production by muramyl dipeptide. J. Neurochem. 99, 596-607.

Lehner, M.D., Morath, S., Michelsen, K.S., Schumann, R.R., Hartung, T., 2001. Induction of cross-tolerance by lipopolysaccharide and highly purified lipoteichoic acid via different toll-like receptors independent of paracrine mediators. J. Immunol. 166, 5161-5167.

Liljeroos, M., Vuolteenaho, R., Morath, S., Hartung, T., Hallman, M., Ojaniemi, M., 2007. Bruton's tyrosine kinase together with PI 3-kinase are part of toll-like receptor 2 multiprotein complex and mediate LTA induced toll-like receptor 2 responses in macrophages. Cell Signal. 19, 625-633.

Lotz, S., Aga, E., Wilde, I., van Zandbergen, G., Hartung, T., Solbach, W., Laskay, T., 2004. Highly purified lipoteichoic acid activates neutrophil granulocytes and delays their spontaneous apoptosis via CD14 and TLR2. J. Leukoc. Biol. 75, 467-477.

Lotz, S., Starke, A., Ziemann, C., Morath, S., Hartung, T., Solbach, W., Laskay, T., 2006. Beta-lactam antibioticinduced release of lipoteichoic acid from Staphylococcus aureus leads to activation of neutrophil granulocytes. Ann. Clin. Microbiol. Antimicrob. 5, 15.

Lund, S., Porzgen, P., Mortensen, A.L., Hasseldam, H., Bozyczko-Coyne, D., Morath, S., Hartung, T., Bianchi, M., Ghezzi, P., Bsibsi, M., Dijkstra, S., Leist, M., 2005. Inhibition of microglial inflammation by the MLK inhibitor CEP-1347. J. Neurochem. 92, 1439-1451.

Lynch, N.J., Roscher, S., Hartung, T., Morath, S., Matsushita, M., Maennel, D.N., Kuraya, M., Fujita, T., Schwaeble, W.J., 2004. L-ficolin specifically binds to lipoteichoic acid, a cell wall constituent of gram-positive bacteria, and activates the lectin pathway of complement. J. Immunol. 172, 1198-1202.

Mancuso, G., Tomasello, F., Ofek, I., Teti, G., 1994. Antilipoteichoic acid antibodies enhance release of cytokines by monocytes sensitized with lipoteichoic acid. Infect. Immun. 62, 1470-1473.

Mattsson, E., Hartung, T., Morath, S., Egesten, A., 2004. Highly purified lipoteichoic acid from Staphylococcus aureus induces procoagulant activity and tissue factor expression in human monocytes but is a weak inducer in whole blood: comparison with peptidoglycan. Infect. Immun. 72, 4322-4326.

Michelsen, K.S., Aicher, A., Mohaupt, M., Hartung, T., Dimmeler, S., Kirschning, C.J., Schumann, R.R., 2001. The role of toll-like receptors (TLRs) in bacteria-induced maturation of murine dendritic cells (DCS). Peptidoglycan 
and lipoteichoic acid are inducers of DC maturation and require TLR2. J. Biol. Chem. 276, 25680-25686.

Morath, S., Geyer, A., Hartung, T., 2001. Structure-function relationship of cytokine induction by lipoteichoic acid from Staphylococcus aureus. J. Exp. Med. 193, 393-397.

Morath, S., Stadelmaier, A., Geyer, A., Schmidt, R.R., Hartung, T., 2002a. Synthetic lipoteichoic acid from Staphylococcus aureus is a potent stimulus of cytokine release. J. Exp. Med. 195, 1635-1640.

Morath, S., Geyer, A., Spreitzer, I., Hermann, C., Hartung, T., 2002b. Structural decomposition and heterogeneity of commercial lipoteichoic acid preparations. Infect. Immun. 70, 938-944.

Morath, S., von Aulock, S., Hartung, T., 2005. Structure/ function relationships of lipoteichoic acids. J. Endotoxin Res. 11, 348-356.

Morr, M., Takeuchi, O., Akira, S., Simon, M.M., Mühlradt, P.F., 2002. Differential recognition of structural details of bacterial lipopeptides by toll-like receptor. Eur. J. Immunol. 32, 3337-3347.

Mueller, M., Stamme, C., Draing, C., Hartung, T., Seydel, U., Schromm, A.B., 2006. Cell activation of human macrophages by lipoteichoic acid is strongly attenuated by lipopolysaccharide-binding protein (LBP). J. Biol. Chem. 281, 31448-31456.

Netea, M.G., Sutmuller, R., Hermann, C., Van der Graaf, C.A., Van der Meer, J.W., van Krieken, J.H., Hartung, T., Adema, G., Kullberg, B.J., 2004. Toll-like receptor 2 suppresses immunity against Candida albicans through induction of IL-10 and regulatory T cells. J. Immunol. 172, 3712-3718.

Opitz, B., Schroder, N.W., Spreitzer, I., Michelsen, K.S., Kirschning, C.J., Hallatschek, W., Zahringer, U., Hartung, T., Gobel, U.B., Schumann, R.R., 2001. Toll-like receptor-2 mediates Treponema glycolipid and lipoteichoic acid-induced NF-kappa B translocation. J. Biol. Chem. 276, 22041-22047.

Palumbo, E., Deghorain, M., Cocconcelli, P.S., Kleerebezem, M., Geyer, A., Hartung, T., Morath, S., Hols, P., 2006. Dalanyl ester depletion of teichoic acids in Lactobacillus plantarum results in a major modification of lipoteichoic acid composition and cell wall perforations at the septum mediated by the Acm2 autolysin. J. Bacteriol. 188, 3709-3715.

Pfeiffer, A., Bottcher, A., Orso, E., Kapinsky, M., Nagy, P., Bodnar, A., Spreitzer, I., Liebisch, G., Drobnik, W., Gempel, K., Horn, M., Holmer, S., Hartung, T., Multhoff, G., Schutz, G., Schindler, H., Ulmer, A.J., Heine, H., Stelter, F., Schutt, C., Rothe, G., Szollosi, J., Damjanovich, S., Schmitz, G., 2001. Lipopolysaccharide and ceramide docking to CD14 provokes ligand-specific receptor clustering in rafts. Eur. J. Immunol. 31, 3153-3164.

Scheel, O., Papavlassopoulos, M., Blunck, R., Gebert, A., Hartung, T., Zahringer, U., Seydel, U., Schromm, A.B., 2006. Cell activation by ligands of the toll-like receptor and interleukin-1 receptor family depends on the function of the large-conductance potassium channel MaxiK in human macrophages. Infect. Immun. 74, 43544356

Schroder, N.W., Hermann, C., Hamann, L., Gobel, U.B., Hartung, T., Schumann, R.R., 2003a. High frequency of polymorphism Arg753Gln of the toll-like receptor-2 gene detected by a novel allele-specific PCR. J. Mol. Med. 81, 368-372.

Schroder, N.W., Morath, S., Alexander, C., Hamann, L. Hartung, T., Zahringer, U., Gobel, U.B., Weber, J.R., Schumann, R.R., 2003b. Lipoteichoic acid (LTA) of Streptococcus pneumoniae and Staphylococcus aureus activates immune cells via toll-like receptor (TLR)-2, lipopolysaccharide-binding protein (LBP), and CD14, whereas TLR-4 and MD-2 are not involved. J. Biol. Chem. 278, 15587-15594.

Smith, R.L., Chong, T.W., Hughes, M.G., Hedrick, T.L., Evans, H.L., McElearney, S.T., Saalwachter, A.R., Raymond, D.P., Du, K., Rudy, C.K., Pruett, T.L., Sawyer, R.G., 2004. Impact of immunomodulatory oligodeoxynucleotides on cytokine production in the lipopolysaccharidestimulated human whole blood model. Surgery 136, 464-472.

Spiller, S., Dreher, S., Meng, G., Grabiec, A., Thomas, W., Hartung, T., Pfeffer, K., Hochrein, H., Brade, H., Bessler, W., Wagner, H., Kirschning, C.J., 2007. Cellular recognition of trimyristoylated peptide or enterobacterial lipopolysaccharide via both TLR2 and TLR4. J. Biol. Chem. 282, 13190-13198.

Stadelmaier, A., Morath, S., Hartung, T., Schmidt, R.R., 2003. Synthesis of the first fully active lipoteichoic acid. Angew. Chem. Int. Ed. Engl. 42, 916-920.

Stadelmaier, A., Figueroa-Perez, I., Deininger, S., von Aulock, S., Hartung, T., Schmidt, R.R., 2006. A Staphylococcus aureus lipoteichoic acid (LTA) derived structural variant with two diacylglycerol residues. Bioorg. Med. Chem. 14, 6239-6254.

Stoll, H., Dengjel, J., Nerz, C., Gotz, F., 2005. Staphylococcus aureus deficient in lipidation of prelipoproteins is attenuated in growth and immune activation. Infect. Immun. 73, 2411-2423.

Theiner, G., Rossner, S., Dalpke, A., Bode, K., Berger, T., Gessner, A., Lutz, M.B., 2008. TLR9 cooperates with TLR4 to increase IL-12 release by murine dendritic cells. Mol. Immunol. 45, 244-252.

Traub, S., Kubasch, N., Morath, S., Kresse, M., Hartung, T., Schmidt, R.R., Hermann, C., 2004. Structural requirements of synthetic muropeptides to synergize with lipopolysaccharide in cytokine induction. J. Biol. Chem. 279, 8694-8700.

Traub, S., von Aulock, S., Hartung, T., Hermann, C., 2006. MDP and other muropeptides - direct and synergistic effects on the immune system. J. Endotoxin Res. 12, 69-85.

Travassos, L.H., Girardin, S.E., Philpott, D.J., Blanot, D., Nahori, M.A., Werts, C., Boneca, I.G., 2004. Toll-like receptor 2-dependent bacterial sensing does not occur via peptidoglycan recognition. EMBO Rep 5, 1000-1006.

Triantafilou, M., Manukyan, M., Mackie, A., Morath, S., Hartung, T., Heine, H., Triantafilou, K., 2004a. Lipoteichoic acid and toll-like receptor 2 internalization and targeting to the Golgi is lipid raft dependent. J. Biol. Chem. 279, 40882-40889.

Triantafilou, M., Morath, S., Mackie, A., Hartung, T., Triantafilou, K., 2004b. Lateral diffusion of toll-like receptors reveals that they are transiently confined within 
lipid rafts on the plasma membrane. J. Cell Sci. 117, 4007-4014.

Triantafilou, M., Gamper, F.G., Haston, R.M., Mouratis, M.A., Morath, S., Hartung, T., Triantafilou, K., 2006 Membrane sorting of toll-like receptor (TLR)-2/6 and TLR2/1 heterodimers at the cell surface determines heterotypic associations with $\mathrm{cd} 36$ and intracellular targeting. J. Biol. Chem. 281, 31002-31011.

van de Wetering, J.K., van Eijk, M., van Golde, L.M., Hartung, T., van Strijp, J.A., Batenburg, J.J., 2001. Characteristics of surfactant protein $\mathrm{A}$ and $\mathrm{D}$ binding to lipoteichoic acid and peptidoglycan, 2 major cell wall components of gram-positive bacteria. J. Infect. Dis. 184, 1143-1151.

von Aulock, S., Morath, S., Hareng, L., Knapp, S., van Kessel, K.P., van Strijp, J.A., Hartung, T., 2003. Lipoteichoic acid from Staphylococcus aureus is a potent stimulus for neutrophil recruitment. Immunobiology 208, 413-422.

von Aulock, S., Schroder, N.W., Traub, S., Gueinzius, K., Lorenz, E., Hartung, T., Schumann, R.R., Hermann, C., 2004. Heterozygous toll-like receptor 2 polymorphism does not affect lipoteichoic acid-induced chemokine and inflammatory responses. Infect. Immun. 72, 1828-1831. von Aulock, S., Hartung, T., Hermann, C., 2007. Comment on "Not lipoteichoic acid but lipoproteins appear to be the dominant immunobiologically active compounds in Staphylococcus aureus". J. Immunol. 178, 2610.

Wasilauskas, B., Morrell Jr., R., 1994. Inhibitory effect of the Isolator blood culture system on growth of Mycobacterium avium-M. intracellulare in BACTEC 12B bottles. J. Clin. Microbiol. 32, 654-657.

Whittier, P.S., Westfall, K., Setterquist, S., Hopfer, R.L., 1992. Evaluation of the Septi-Chek AFB system in the recovery of mycobacteria. Eur. J. Clin. Microbiol. Infect. Dis. 11, 915-918.

Wicken, A.J., Knox, K.W., 1975. Lipoteichoic acids: a new class of bacterial antigen. Science 187, 1161-1167.

Yipp, B.G., Andonegui, G., Howlett, C.J., Robbins, S.M., Hartung, T., Ho, M., Kubes, P., 2002. Profound differences in leukocyte-endothelial cell responses to lipopolysaccharide versus lipoteichoic acid. J. Immunol. 168, 4650-4658.

Zeidler, D., Zahringer, U., Gerber, I., Dubery, I., Hartung, T., Bors, W., Hutzler, P., Durner, J., 2004. Innate immunity in Arabidopsis thaliana: lipopolysaccharides activate nitric oxide synthase (NOS) and induce defense genes. Proc. Natl. Acad. Sci. USA 101, 15811-15816. 